\title{
Biosynthesis of Silver and Gold Nanoparticles: Effect of Microwave Irradiation
}

\author{
B. Ahmmad", J. Kurawaki, K. Leonard, and Y. Kusumoto \\ Department of Chemistry and Bioscience, Graduate School of Science and Engineering \\ Kagoshima University, 1-21-35 Korimoto, Kagoshima 890-065, Japan
}

Received 11 May 2010, accepted in revised form 17 July 2010

\begin{abstract}
A simple and fast synthesis method of gold and silver nanoparticles without any surfactant or reducing agent has been developed by using the extract of green tea (camellia sinensis) under microwave irradiation. The synthesized gold and silver colloidal nanoparticles were spherical in shape and have an average diameter of 13 and $17 \mathrm{~nm}$ for $\mathrm{Au}$ and $\mathrm{Ag}$ nanoparticles, respectively. The as-synthesized nanoparticles were characterized by TEM, XRD, XPS, and UV-visible spectroscopy.
\end{abstract}

Keywords: Microwave; Gold; Silver; Nanoparticles; Biosynthesis.

(c) 2010 JSR Publications. ISSN: 2070-0237 (Print); 2070-0245 (Online). All rights reserved.

DOI: 10.3329 /jsr.v2i3.4993 J. Sci. Res. 2 (3), 495-500 (2010)

\section{Introduction}

Unique electronic and chemical properties of metal nanoparticles have drawn the attention of chemists, physicists, biologists, and engineers who wish to use them for the development of new generation nanodevices [1]. Among various metallic nanoparticles gold and silver have attracted more attention because they have many color varieties in visible region based on plasmon resonance, which is due to the collective oscillations of the electrons at the surface of the nanoparticles. The resonance wavelength strongly depends on the size and shape of the nanoparticles, the interparticle distance and the dielectric properties of the surrounding medium [2]. To control their size and morphology various methods for the preparation of Au nanoparticles have been employed such as chemical and physical methods [3]. Unfortunately, many of the nanomaterials synthesis or production methods involve the uses of hazardous chemicals, low material conversions, high energy requirements, and difficult, wasteful purifications. Use of biological organisms such as microorganisms, plant extract or plant biomass could be an alternative

${ }^{*}$ Corresponding author: b.ahmmad5@gmail.com 
to chemical and physical methods for the production of nanoparticles in an eco-friendly manner [4]. Recently, Vilchis-Nesto et al. [5] reported the synthesis of $\mathrm{Au}$ and $\mathrm{Ag}$ nanoparticles by using the extract of green tea at room temperature [5]. They also reported that an aqueous extract of green tea contains phenolic compounds and terpenoids among the major bio-components, which have bactericidal and antioxidant activity. These type of compounds contribute to the metal ion reduction processes and their chemical framework is also effective at wrapping around the nanoparticles to provide excellent robustness against agglomeration. But, in their studies the synthesized Au or Ag nanoparticles were somewhat irregular with an average size of $40 \mathrm{~nm}$ and the time required for reactions were about 15 and 45 min for $\mathrm{Au}$ and Ag nanooparticles, respectively. But the application of $\mathrm{Au}$ and $\mathrm{Ag}$ nanoparticles in the catalysis is dependent on the shape, size, monodispersity and chemical composition. Here we report the effect of microwave irradiation on the size and shape of nanoparticles during the formation of $\mathrm{Au}$ and $\mathrm{Ag}$ nanoparticles by using the extract of green tea. In our method most of the $\mathrm{Au}$ and $\mathrm{Ag}$ nanoparticles were uniformly spherical with size around 15 to $20 \mathrm{~nm}$ for both samples. Moreover, this method is about 20 to 30 times faster and economical than the reported methods.

\section{Experimental}

The fresh green tea leaves were collected from the local garden in Kagoshima, Japan. The solution of green tea was prepared by heating $2 \mathrm{~g}$ of green tea leaves in $150 \mathrm{ml}$ water for $10 \mathrm{~min}$ at $100^{\circ} \mathrm{C}$ by a hotplate. The green tea solution was filtered and stored at $10^{\circ} \mathrm{C}$. In a flask $1 \mathrm{~g}$ of chloroauric acid $\left(\mathrm{HAuCl}_{4} \cdot 4 \mathrm{H}_{2} \mathrm{O}\right.$, Wako, 99.9\%) was dissolved in $100 \mathrm{ml}$ distilled water. $0.5 \mathrm{ml}$ of chloroauric acid solution was taken in a conical flask and adjusted the total volume to $50 \mathrm{ml}$ by adding distilled water. Then 20 drops of green tea solution were added to this solution. The reaction was completed by stirring the solution with or without heating on a hot plate. For the microwave mediated nanoparticles, the similar amount of aqueous chloroauric acid and green tea extract were taken in a conical flask and irradiated in a domestic microwave oven (Sharp, R-83T, $100 \mathrm{~W}$ ) for $1 \mathrm{~min}$ when the red color of $\mathrm{Au}$ nanoparticles was appeared. For Ag nanoparticles, $100 \mu \mathrm{l}$ of $0.025 \mathrm{M}$ $\mathrm{AgNO}_{3}$ (Wako, 99.8) was dissolved in $50 \mathrm{ml}$ of water and put under microwave irradiation for $1.5 \mathrm{~min}$. Care was taken that solution does not come out of flask due to high temperature.

The UV-visible spectra of the nanoparticles were recorded using a UV-visible spectrophotometer (Shimazu, UV-1800). The size and surface condition of the submicrospheres were analyzed by transmission electron micrograph (TEM, JEOL, JEM-3010 VII, operating at $300 \mathrm{kV}$ ). Crystal structure identification was made by X-ray diffraction (XRD) using a PANalytical Advance X-ray diffractometer with $\mathrm{CuK} \alpha$ radiation. The XPS patterns were recorded on an X-ray photoelectron spectrometer (Shimadzu, ESCA-1000) using MgK $\alpha$ X-ray as the excitation source. 


\section{Results and Discussion}

Fig 1 $(a, b)$ shows the TEM images of Au nanoparticles prepared by the extract of green tea at room temperature $\left(\mathrm{Au}_{\mathrm{rt}}\right)$ and under microwave irradiation $\left(\mathrm{Au}_{\mathrm{mw}}\right)$. The results obtained from the TEM study give a clear indication regarding the shape and size of the nanoparticles. $\mathrm{Au}_{\mathrm{rt}}$ has a wide range of size variation (Fig. 1a) and such variation in size and shape of nanoparticles synthesized by biological systems is common. But majority of the $\mathrm{Au}_{\mathrm{mw}}$ nanoparticles were spherical in shape and appeared to be reasonably monodispersed (Fig. 1b). The average diameters of the $\mathrm{Au}_{\mathrm{rt}}$ and $\mathrm{Au}_{\mathrm{mw}}$ nanoparticles are shown by histograms in Fig. $1 \mathrm{c}$. The $\mathrm{Au}_{\mathrm{rt}}$ particles are comparatively large in size and the size ranges from 5 to $30 \mathrm{~nm}$. Whereas, $\mathrm{Au}_{\mathrm{mw}}$ particles have homogeneous and small sizes ranging from 10 to $15 \mathrm{~nm}$. The similar effect on size is observed in case of reaction carried out at $100^{\circ} \mathrm{C}$ but reaction takes about $5 \mathrm{~min}$. It can be concluded from these results that the microwave method is a faster method and uniform sized particles can be produced. In case of reaction at room temperature, the completion of reaction process is slow (about $10 \mathrm{~min}$ ) and thus irregular sized particles are produced. But in case of microwave irradiation the temperature of the reactant solution is swiftly increased and completion of reduction process takes place in a short time, resulting in fine and uniform particles.
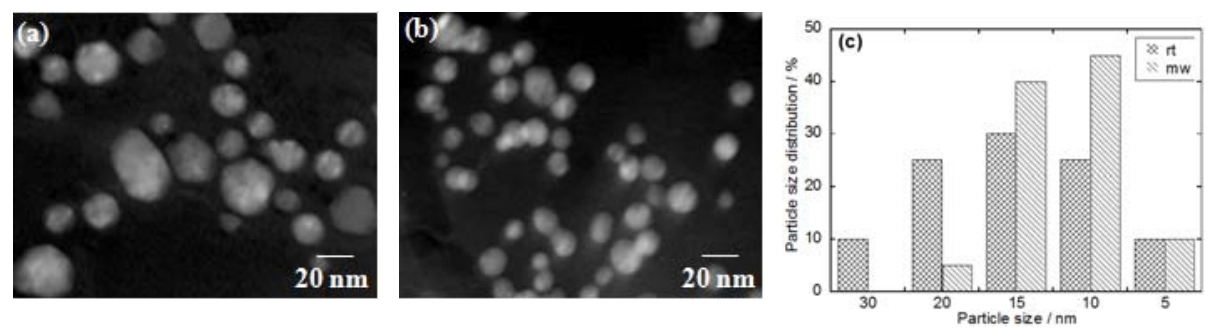

Fig. 1 TEM images of Au nanoparticles prepared at room temperature (a) and under microwave irradiation (b); particle size distribution histogram (c).

Comparatively strong effect of microwave irradiation is observed in case of $\mathrm{Ag}$ nanoparticles as seen in the TEM images of Fig. 2(a, b). The size distribution histogram shows that the particles of $\mathrm{Ag}_{\mathrm{rt}}$ have a size range of 5 to $40 \mathrm{~nm}$ (Fig. 2c) and the time required for the completion of reaction is about $1 \mathrm{~h}$. Whereas the time required for completion of reaction under microwave irradiation is only 1.5 min and most of the $\mathrm{Ag}_{\mathrm{mw}}$ nanoparticles are within the size range of 10 to $25 \mathrm{~nm}$. The comparatively slower reduction rate of silver ions relative to that of gold ions is most likely due to difference in reduction potentials of the two metal ions, the redox potential being considerably lower for $\mathrm{Ag}^{+}$to $\mathrm{Ag}^{0}$ [6]. 

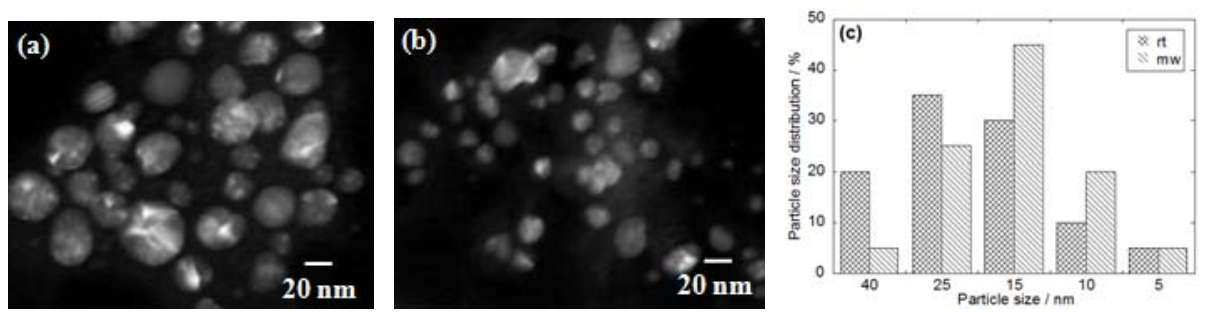

Fig. 2 TEM images of Ag nanoparticles prepared at room temperature (a) and under microwave irradiation (b); particle size distribution histogram (c).

The UV-vis and XRD spectra of as-prepared Au and Ag nanoparticles are shown in Fig $3(a, b)$. From the UV-visible spectra of the prepared nanoparticles in Fig. 3a, we can see strong absorption peaks at 450 and $530 \mathrm{~nm}$ for spherical $\mathrm{Ag}$ and $\mathrm{Au}$ nanoparticles, respectively. The XRD spectrum confirms the crystalline nature of the particle as represented in Fig. 3b. On the XRD pattern of $\mathrm{Ag}_{\mathrm{mw}}$ nanoparticles, diffraction peaks at $38.13^{\circ}, 44.21^{\circ}, 64.47^{\circ}$, and $77.37^{\circ}$ can be assigned to face-centered cubic (FCC) metallic
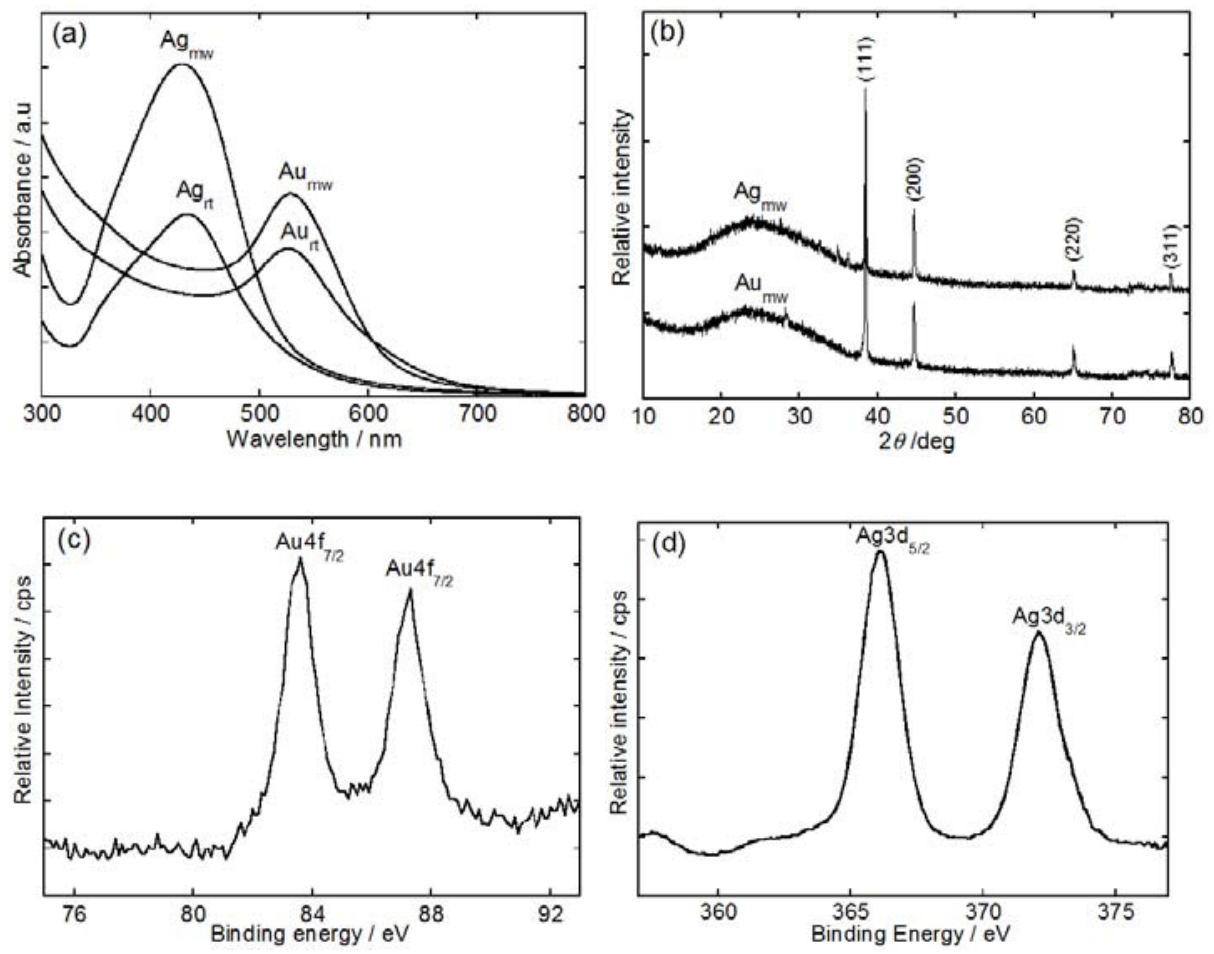

Fig. 3 UV-visible (a) and XRD (b) spectra for Au and Ag nanoparticles; XPS spectra of Au (c) and $\mathrm{Ag}(\mathrm{d})$ nanoparticles. 
silver [7] and no peaks of other impurity crystalline phases were detected. In case of gold, the characteristic diffraction peaks of FCC metallic gold phase at $38.21^{\circ}, 44.39^{\circ}$, $64.62^{\circ}$, and $77.59^{\circ}$ can be observed. For the both $\mathrm{Ag}_{\mathrm{mw}}$ and $\mathrm{Au}_{\mathrm{mw}}$ nanoparticles the peak corresponding to the $\left(\begin{array}{lll}1 & 1 & 1\end{array}\right)$ plane is more intense than the other planes suggesting that the (1 11 1) plane is the predominant orientation [7].

The X-ray photoelectron spectroscopy (XPS) was used to study for the surface composition and electronic states of the $\mathrm{Au}_{\mathrm{mw}}$ and $\mathrm{Ag}_{\mathrm{mw}}$ nanoparticles. Fig. $3 \mathrm{c}$ shows the typical gold XPS spectra of $4 \mathrm{f}$ orbital in the as-deposited film. The spectra show the binding energies of $\mathrm{Au} 4 \mathrm{f}_{7 / 2}$ at 83.8 and $\mathrm{Au} 4 \mathrm{f}_{5 / 2}$ at $87.45 \mathrm{eV}$ corresponding to the standard gold [8] the former of which is also found to be significantly different from $\mathrm{Au}^{+} 4 \mathrm{f}_{7 / 2}(84.6$ $\mathrm{eV})$ and $\mathrm{Au}^{3+} 4 \mathrm{f}_{7 / 2}(87.0 \mathrm{eV})$ but similar to $\mathrm{Au}^{0} 4 \mathrm{f}_{7 / 2}(84.0 \mathrm{eV})$. The XPS results suggest that the $\mathrm{Au}$ species are present in the metallic state and their surface have no charge. Fig. $3 d$ shows the binding energies for Ag electron configurations of $3 d_{5 / 2}$ and $3 d_{3 / 2}$ of 366.1 $\mathrm{eV}$ and $372.1 \mathrm{eV}$, respectively with a difference of $6.0 \mathrm{eV}$. This is comparable to the standard $\mathrm{Ag} 3 \mathrm{~d}$ binding energies $\left(3 \mathrm{~d}_{5 / 2}=368.3 \mathrm{eV}, 3 \mathrm{~d}_{3 / 2}=374.3 \mathrm{eV}, \Delta=6.0 \mathrm{eV}\right)$ [8] suggesting that the $\mathrm{Ag}$ species are present in the metallic state.

\section{Conclusion}

Microwave irradiation was successfully applied to prepare uniform and smaller nanoparticles of $\mathrm{Au}$ and $\mathrm{Ag}$. Since noble metal nanoparticles are widely applied in human body, uniform sized smaller particles are necessary. This spanking new and simple method for biosynthesis of silver and gold nanoparticles offers a valuable contribution in the area of green synthesis and biomedical applications. It is expected that this method is also applicable for the preparation of other metal particles with uniform size and shapes.

\section{Acknowledgements}

We gratefully acknowledge Japan Society for the Promotion of Science (JSPS) for the postdoctoral fellowship award to B.A. This work was partly supported by Grant-in-Aid for Scientific Research (B) (No. 19360367) and Grant-in-Aid for JSPS Fellows (No.20·08081). The authors also wish to thank Mr. Masao Arima of Kagoshima prefecture for providing fresh green tea leaves.

\section{References}

1. P. V. Kamat, J. Phys. Chem. B 106, 7729 (2002). doi:10.1021/jp0209289

2. M.-C. Daniel, D. Astruc, Chem. Rev. 104, 293 (2004). doi:10.1021/cr030698+

3. M. Abdulla-Al-Mamun, Y. Kusumoto, A. Mihata, M. S. Islam, B. Ahmmad, Photochem. Photobiol. Sci. 8, 1125 (2009). doi:10.1039/b907524k

4. V. Kumar, S. K. Yadav, J Chem. Technol. Biotechnol. 84, 151 (2009). doi:10.1002/jctb.2023

5. A. R. Vilchis-Nestor, V. Sánchez-Mendieta, M. A. Camacho-López, R. M. Gómez-Espinosa, M. A. Camacho-López, J. A. Arenas-Alatorre, Mater. Lett. 62, 3103 (2008). doi:10.1016/j.matlet.2008.01.138

6. D. Philip, Spectrochimica Acta Part A 73, 374 (2009). doi:10.1016/j.saa.2009.02.037 
7. S. P. Dubey, M. Lahtinen, M. Sillanpää, Proc. Biochem. 45, 1065 (2010). doi:10.1016/j.procbio.2010.03.024

8. C.D. Wagner, G.E. Muilenberg (Eds.), Handbook of X-ray Photoelectron Spectroscopy: A Reference Book of Standard Data for Use in X-ray Photoelectron Spectroscopy, 1st ed. (Physical Electronics Division, Perkin-Elmer Corp., Eden Prairie, MN, 1979) pp. 121-154. 